\title{
Casamino acids facilitate the secretion of recombinant dengue virus serotype-3 envelope domain III in Pichia pastoris
}

\author{
Neha Kaushik', Deepak Rohila', Upasana Arora², Rajendra Raut², Urpo Lamminmäki ${ }^{3}$, Navin Khanna² \\ and Gaurav Batra ${ }^{*}$
}

\begin{abstract}
Background: Dengue is a viral disease spread to humans by mosquitoes. Notably, there are four serotypes of dengue viruses (DENV) that places $\sim 40 \%$ of the global population at risk of infection. However, lack of a suitable drug or a preventive vaccine exacerbates the matter further. Envelope domain-III (EDIII) antigen of dengue virus (DENV) has garnered much attention as a promising vaccine candidate for dengue, in addition to its use as a diagnostic intermediate. Hence developing a method for efficient production of high quality recombinant EDIII is important for research and industrial purpose.

Results: In this work, a Pichia pastoris system was optimized for the secretory over-expression of DENV serotype-3 EDIII under the control of methanol inducible AOX1 promoter. Temperature alone had a significant impact upon the amount of secretory EDIII, with 2.5-fold increase upon reducing the induction temperature from 30 to $20^{\circ} \mathrm{C}$. However surprisingly, supplementation of culture media with Casamino acids (CA), further augmented secretory EDIII titer, with a concomitant drop of intracellular EDIII levels at both temperatures. Though, reduction in intracellular retention of EDIII was more prominent at $20^{\circ} \mathrm{C}$ than $30^{\circ} \mathrm{C}$. This suggests that CA supplementation facilitates overexpressing P. pastoris cells to secrete more EDIII by reducing the proportion retained intracellularly. Moreover, a bell-shaped correlation was observed between CA concentration and secretory EDIII titer. The maximum EDIII expression level of $187 \mathrm{mg} / \mathrm{L}$ was achieved under shake flask conditions with induction at $20^{\circ} \mathrm{C}$ in the presence of $1 \% \mathrm{CA}$. The overall increase in EDIII titer was $\sim 9$-fold compared to un-optimized conditions. Notably, mouse immune-sera, generated using this purified EDIII antigen, efficiently neutralized the DENV.
\end{abstract}

Conclusions: The strategy described herein could enable fulfilling the mounting demand for recombinant EDIII as well as lay direction to future studies on secretory expression of recombinant proteins in $P$. pastoris with CA as a media supplement.

Keywords: Casamino acids, Dengue virus, Envelope domain III, Pichia Pastoris, Secretion

\section{Background}

Dengue, a mosquito-borne disease, can be caused by four antigenically distinct serotypes of dengue viruses (DENVs). Recent analysis suggests that DENVs causes as many as 390 million (95\% credible interval 284-528) infections annually [1]. However, there is no vaccine or drug available in the market to fight against this global

\footnotetext{
* Correspondence: gaurav.batra@thsti.res.in

${ }^{1}$ Centre for Biodesign and Diagnostics, Translational Health Science and Technology Institute, NCR Biotech Science Cluster, Faridabad, Haryana, India

Full list of author information is available at the end of the article
}

public health problem. Accumulating evidences indicate the potential of dengue virus (DENV) Envelope Domain III (EDIII) as a possible vaccine candidate, in addition to its usage as a highly specific diagnostic intermediate and a plausible target for neutralizing therapeutic antibodies [2]. EDIII, that spans amino acid (aa) residues 297-400 of the $\mathrm{E}$ protein, is an immunoglobulin (Ig)-like domain. It is implicated in the binding of the virion to the host cell surface receptor and contains multiple type and subtype specific neutralizing epitopes [3]. Identity amongst the EDIIIs of the four DENV serotypes is 60-70\% 
(Additional file 1: Figure S1), yet these domains are antigenically distinct and can be used for the serotyping of immune response [2, 4]. Because of its unique features, recombinant versions of EDIII have also found extensive utility in basic research, for understanding host-virus interactions, and immune response against natural infection [2,3].

Numerous expression systems have been reported for the production of recombinant EDIII from different DENV serotypes, however E. coli remains the most widely used expression host [4-6]. Soluble expression of EDIII in E.coli involves the fusion of protein with a large solubility tag, such as MBP [5]. In the absence of a solubility tag, overexpressed EDIII tends to be insoluble and hence necessitates purification under denaturing conditions, followed by renaturation $[4,6]$.

The yeast Pichia pastoris offers several advantages as a protein production host. It harbors a strong yet tightly regulated alcohol oxidase I (AOX1) promoter that allows for efficient expression of recombinant protein. P. pastoris also allows for very high levels of extracellular secretion of recombinant protein into culture media with minimal secretion of endogenous proteins [7].

Use of $P$. pastoris for the secretory expression of DENV serotype-2 EDIII with shake flask, achieving titer of $2.2 \mathrm{mg} / \mathrm{L}$, and bioreactor, achieving titer of $172 \mathrm{mg} / \mathrm{L}$ has been reported [8]. Secretion of DENV serotype-1 EDIII in $P$. pastoris has also been shown but without any information on the titer of the secreted protein [9].

Here we report the construction and optimization of a secretory $P$. pastoris clone of DENV serotype-3 EDIII for high-level secretion of EDIII into minimal media. We show for the first time a dosing effect of CA supplementation in culture media on the secretory expression of recombinant protein in $P$. pastoris. Our data clearly suggest that $\mathrm{CA}$ supplementation increases the secretory titer of recombinant EDIII by reducing the intracellular retention of recombinant protein.

\section{Methods}

\section{Reagents}

Anti-penta His mAb, Ni-NTA superflow resin and NiNTA His-Sorb plates were procured from Qiagen $\mathrm{GmbH}$, Germany. Anti-mouse IgG-H\&L-chain-HRP-conjugate was from JIR, USA. Acid washed glass beads (425-600 microns), HRP substrate TMB were from Sigma-Aldrich, USA. Montanide ISA720 was from Seppic Inc., France. BCA protein assay reagent was from Thermo Scientific, Rockford, USA. Vero cell lines and Pan-DENV prMspecific $2 \mathrm{H} 2 \mathrm{mAb}$ were obtained from ATCC, USA. DENV EDIII-specific mAb 24A12 was generated inhouse. Alexa Fluor 488 for labeling mAbs was from Life Technologies. N1-Europium chelate was synthesized inhouse at University of Turku, Finland. DENV-3 EDIII gene, codon-optimized for $P$. pastoris expression, was obtained from GeneArt AG, Germany. Casamino Acids (Bacto casamino acids: acid-hydrolyzed casein, low sodium chloride and iron concentrations) Cat \# 223050 from Becton, Dickinson and company, USA. CA are a mixture of amino acids and some very small peptides $(<5$ amino acids) obtained from acid hydrolysis of casein.

\section{Generation of DENV-3 EDIII expressing P. pastoris clone}

The synthetic codon-optimized DENV-3 EDIII gene (Additional file 2: Figure S2) was cloned under the control of $A O X 1$ promoter of pPICZ $\alpha$ A vectors (Life Technologies) and integrated into the genome of $P$. pastoris $\mathrm{Mut}^{\mathrm{S}}$ strain $\mathrm{KM} 71 \mathrm{H}$. Keeping future requirements in mind, $\mathrm{Mut}^{\mathrm{s}}$ (methanol utilizing slow) was preferentially selected over a $\mathrm{Mut}^{+}$(methanol utilizing plus) strain owing to the ease of handling of the former during large-scale production. In contrast to $\mathrm{Mut}^{+}$, methanol accumulation does not hyper-accelerate the growth of $\mathrm{Mut}^{\mathrm{s}}$, and hence enables better control over heat and oxygen demand during large-scale production [10].

Transformants obtained through zeocin selection, were screened for EDIII expression. Test tube cultures of 30 EDIII transformants and 1 negative control (KM71H containing empty pPICZ $\alpha \mathrm{A})$ were set up in $3 \mathrm{ml} \mathrm{YPD}$ and incubated for $72 \mathrm{~h}$ at $30{ }^{\circ} \mathrm{C}$ with shaking at $300 \mathrm{rpm}$, ensuing equal confluence. From these precultures, $50 \mu \mathrm{l}$ aliquots were used to inoculate $8 \mathrm{ml}$ buffered glycerol-complex media (BMGY) $[1 \%$ yeast extract, $2 \%$ peptone, $100 \mathrm{mM}$ Potassium phosphate, $\mathrm{pH} 5.8$; $1.34 \%$ YNB; $4 \times 10^{-5} \%$ Biotin; $1 \%$ Glycerol] in duplicate tubes. Cultures were allowed to shake at $300 \mathrm{rpm}$, at $30{ }^{\circ} \mathrm{C}$ for $30 \mathrm{~h}\left(\mathrm{OD}_{600}=\sim 25\right)$. Cells were pelleted by low speed centrifugation $(1500 \times g)$ and re-suspended in $3 \mathrm{ml}$ buffered methanol-complex media (BMMY) $[1 \%$ yeast extract, $2 \%$ peptone, $100 \mathrm{mM}$ Potassium phosphate, pH 5.8; $1.34 \%$ YNB; $4 \times 10^{-5} \%$ Biotin; $2 \%$ Methanol]. Inductions were maintained for 3 days at $30{ }^{\circ} \mathrm{C}$. During this time, $2 \%(\mathrm{v} / \mathrm{v})$ methanol was added at $24 \mathrm{~h}$ intervals. After 3 days of induction, cultures were centrifuged and supernatant were used for immunoassay for the determination of EDIII secretion.

\section{Culture condition optimization}

The best secretory-clone was used for optimization experiments in shake-flask setting. The growth phase was performed in buffered minimal glycerol (BMG) [100 mM Potassium phosphate, pH 5.8; $1.34 \%$ YNB; $4 \times 10^{-5} \%$ Biotin; $1 \%$ Glycerol] and induction phase in buffered minimal methanol (BMM) [100 mM Potassium phosphate, pH 5.8; $1.34 \%$ YNB; $4 \times 10^{-5} \%$ Biotin; $2 \%$ Methanol]. To optimize culture conditions to increase the secretion level of EDIII protein, effect of induction temperature $\left(20{ }^{\circ} \mathrm{C}\right.$ and $30{ }^{\circ} \mathrm{C}$ ) and $\mathrm{CA}$ supplementation, at different 
concentrations $(0.25,0.5,1.0,1.5$ and $2 \% \mathrm{w} / \mathrm{v})$, in the BMM media was investigated. A starter culture was set up by inoculating $50 \mathrm{ml}$ YPD medium with the P. pastoris EDIII clone \#27 glycerol stock and incubated for $\sim 20 \mathrm{~h}$ at $30{ }^{\circ} \mathrm{C}$ with shaking at $270 \mathrm{rpm}$. This starter was used to inoculate $1500 \mathrm{ml}$ of $\mathrm{BMG}$ to a starting $\mathrm{OD}_{600}=0.08$ and divided equally into three $2 \mathrm{~L}$ baffled flasks $(500 \mathrm{ml}$ each). Culture was allowed to grow at $30{ }^{\circ} \mathrm{C}$ with shaking, at $270 \mathrm{rpm}$, for $\sim 24 \mathrm{~h}\left(\mathrm{OD}_{600}=\sim 30\right)$. Cells were harvested by centrifuging at $1500 \times g$ for $5 \mathrm{~min}$ at RT, and washed with sterile double-distilled water. Cells were resuspended in water to an $\mathrm{OD}_{600}=120$ and $25 \mathrm{ml}$ of this suspension was added into twelve $250 \mathrm{ml}$ baffled flasks prefilled with $25 \mathrm{ml}$ of $2 \times$ BMM media and appropriate $2 \times$ [CA]. The resulting cultures therefore had a starting, $\mathrm{OD}_{600}$ of 60 in $1 \times$ BMM containing different concentration of CA (0, $0.25,0.5,1.0,1.5$ and $2 \% \mathrm{w} / \mathrm{v})$. The initial OD at the start of induction was reconfirmed at $60(+/-0.5)$. Inductions were allowed to proceed for 6 days at $20{ }^{\circ} \mathrm{C}$ ( 6 flasks with $0,0.25,0.5,1.0,1.5$ and $2 \% \mathrm{w} / \mathrm{v} \mathrm{CA})$ and at $30^{\circ} \mathrm{C}$ (6 flasks with $0,0.25,0.5,1.0,1.5$ and $2 \% \mathrm{w} / \mathrm{v}$ CA). Daily methanol feed of $2 \%(\mathrm{v} / \mathrm{v})$ was added in each flask to maintain the induction. In all the above-mentioned cases, culture samples were withdrawn at $24 \mathrm{~h}$ intervals, centrifuged, and the clarified supernatants were collected and further used for SDS-PAGE, western blot and immunoassay. Cell pellets were used for extraction of total intracellular proteins.

\section{Total intracellular protein extraction}

To extract total intracellular protein, a buffer containing strong denaturant was used. Cell pellet of $1 \mathrm{ml}$ culture was re-suspended in $200 \mu \mathrm{l}$ of lysis buffer [6 M Guanidine- $\mathrm{HCl}, 50 \mathrm{mM}$ Dithiothreitol, $50 \mathrm{mM}$ phosphate buffer $\mathrm{pH}$ 7.0]. An equal volume of glass beads were added and cells were allowed to lyse overnight on plate shaker (Eppendorf Mix mate) at $1500 \mathrm{rpm}, 25^{\circ} \mathrm{C}$. The lysed cells were centrifuged and the supernatant containing total protein was collected.

\section{Analytical methods}

EDIII levels were determined using customized immunoassay as reported earlier [8] except the use of Europium labeled anti-EDIII-MAb 24A12 instead of anti-EDIII-MAb $3 \mathrm{H} 5$ coupled with secondary antimouse-HRP. Each sample was assayed in duplicate wells. A reference curve $\left(R^{2}=0.98\right)$, generated in parallel using serially diluted (2-fold) pure DENV-3 EDIII protein (purified as mentioned below) of known concentration (measured using absorbance at $280 \mathrm{~nm}$ ), was used to determine the EDIII levels in crude samples. Western blot analysis was done using anti-EDIII 24A12 mAb \& goat anti-mouse HRP as primary \& secondary antibody respectively. For the clone screening immunoassay, anti-
EDIII 24A12 mAb and goat anti-mouse HRP were used as primary \& secondary antibody respectively.

\section{Large-scale expression and purification}

For the large-scale cultivation and expression of EDIII, essentially the same protocol was followed as stated previously [8], except that BMM media was supplemented with $1 \% \mathrm{CA}$ and induction was performed at $20{ }^{\circ} \mathrm{C}$. The Ni-NTA based protein purification protocol were performed as previously reported [8].

\section{Mice immunization and seroanalysis}

Animal experiments were reviewed and approved by the International Centre for Genetic Engineering and Biotechnology institutional animal ethics committee and adhered to the guidelines of the Government of India. A group of five BALB/c mice (4-6 weeks old) was immunized intraperitoneally on days 0,21 and 42 with $20 \mu \mathrm{g}$ purified EDIII formulated in Montanide ISA 720 adjuvant. Mock immunizations were performed in parallel wherein PBS replaced the antigen solution in the control group. The neutralizing capacity of immune sera were measured using Flow-cytometry based neutralization test (FNT) as described earlier [11]. In the FNT assay, antibodies capable of neutralizing the infectivity of DENV-3 (WHO reference strain CH53489) were measured. Briefly, Vero cells were infected with DENV-3 strain $\mathrm{CH}-53489$ incubated with pooled serum at various dilutions, and the \% of cells infected with the virus were evaluated after $24 \mathrm{~h}$ by staining them with Alexa 488 labeled $2 \mathrm{H} 2 \mathrm{mAb}$ and reading it on flow cytometer. The serum dilution, which resulted in $50 \%$ reduction in the \% of DENV-infected cells in comparison to the control group, has been reported as $\mathrm{FNT}_{50}$. FNT assay for test and mock pooled samples were performed in duplicate wells.

No studies were carried out on or with materials derived from human subjects.

\section{Results and discussion}

Synthetic DENV-3 EDIII gene, cloned in-frame with the $S$. cerevisiae $\alpha$-mating factor secretory signal under the control of methanol inducible AOX1 promoter, was integrated into the genome of $P$. pastoris $\mathrm{Mut}^{\mathrm{S}}$ strain using zeocin selection strategy.

Total 30 colonies were screened in test tube setting using customized immunoassay. One clone, \#27, which secreted the maximal level of EDIII in the culture supernatant (Additional file 3: Figure S3), was used for all further experiments.

This study assesses the effect of low temperature induction and CA supplementation on the secretory titers of DENV-3 EDIII in shake-flask settings. Optimization experiments were performed in minimal media instead 

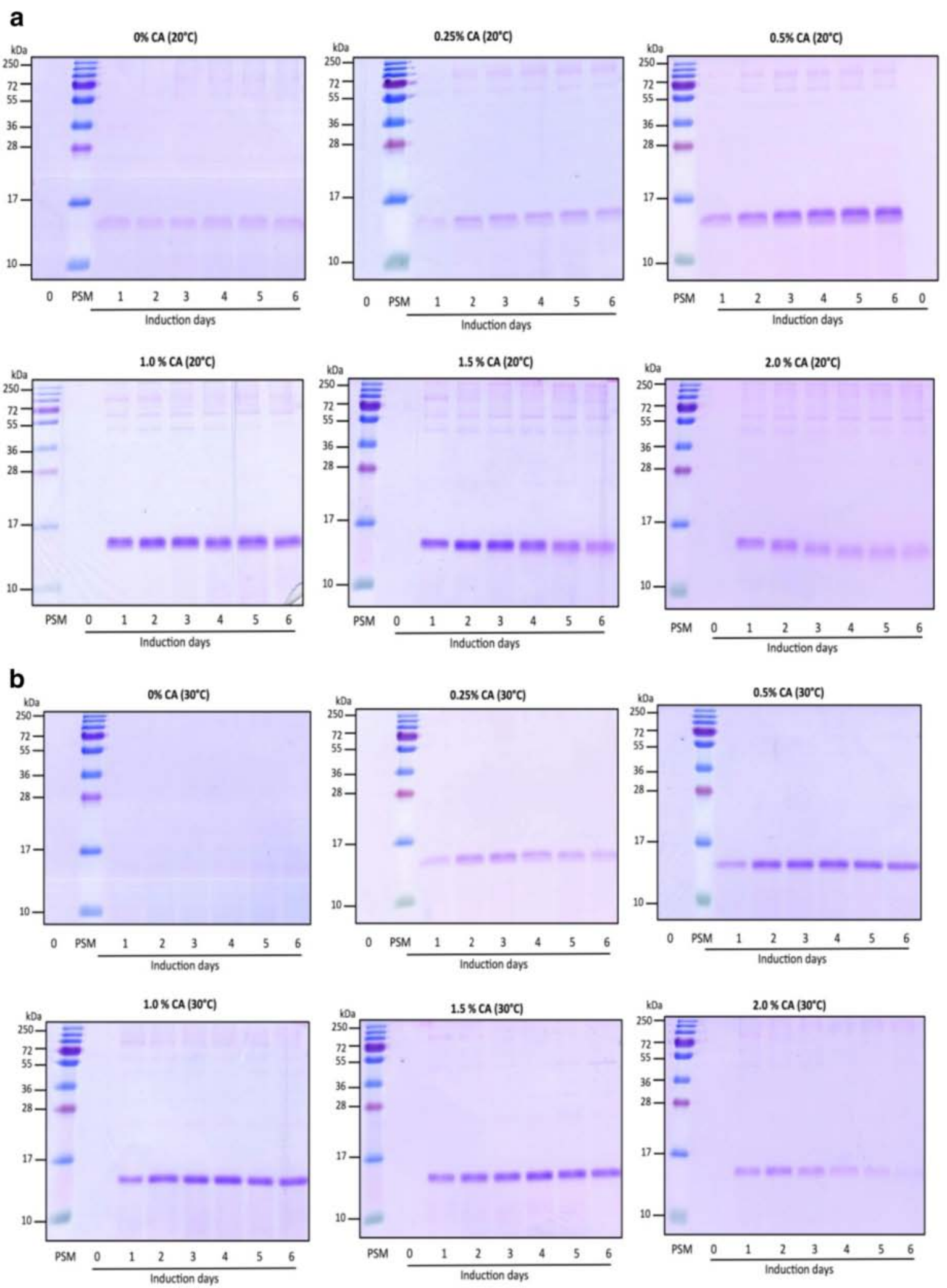

Fig. 1 Coomassie stained SDS-PAGE showing secreted EDIII. Presence of secretory EDIII was determined in the supernatant of cultures induced in the absence (CA $0 \%$ ) or presence of different concentrations of casamino acids (CA $0.25 \%$ to $2.0 \% \mathrm{w} / \mathrm{v}$ ) supplemented BMM media from day 0 to day 6 at $20^{\circ} \mathrm{C}$ (a) and $30^{\circ} \mathrm{C}$ (b). For both panels, similar trends were observed in two independent induction experiments (Additional file 9) 
of complex media (containing yeast extract and peptones) owing to the ease in purification of secreted recombinant protein from minimal media.

The effects of low temperature induction upon protein expression and secretion have been well studied. Higher secretory titers of recombinant protein at lower temperature has been associated with lower cell death [12] and slower translation ensuring reduced ER stress $[13,14]$. In concurrence, induction at $20^{\circ} \mathrm{C}$ had a significant impact upon secreted EDIII titer in our study (Figs. 1 and 2). In contrast to $30{ }^{\circ} \mathrm{C}$, a distinct band corresponding to EDIII $(\sim 14 \mathrm{kDa})$ was observed when the culture was induced at $20{ }^{\circ} \mathrm{C}$ (Fig. 1). The total secreted EDIII in culture supernatant was estimated at $\sim 54 \mathrm{mg} / \mathrm{L}$ broth for $20{ }^{\circ} \mathrm{C}$ as against $\sim 21 \mathrm{mg} / \mathrm{L}$ broth at $30{ }^{\circ} \mathrm{C}$ (Fig. 2). Notably a cognate 1.3 fold higher cell mass was also observed at $20^{\circ} \mathrm{C}$ compared to $30{ }^{\circ} \mathrm{C}$ (Fig. 3), which is consistent with earlier report [12]. However, an increase in accumulation of secreted EDIII was not observed over time.

There are several reports suggesting a positive effect of media supplementation with CA on the titer of secretory proteins in yeast system [15-21]. CA supplementation has been associated with accumulation of secretory protein over a longer induction period [15]. Additionally, some of these studies have also tried to link the beneficial effect of CA with reduction in proteolytic activity in culture media $[15,18,20]$. However hitherto, no report has provided a concrete explanation for the positive effect(s) of CA.

Further, $\mathrm{CA}$ is also an alternative carbon and nitrogen source for cell growth [7]. Moreover, presence of CA in culture media doesn't interfere in the protein purification methods unlike yeast extract and peptones [22]. Hence to enhance EDIII accumulation over time, we decided to attempt CA supplementation. Every report until now, barring one by Toonkool et al [15] (where two concentrations of CA in the media were evaluated), has used a single concentration of CA [16-21, 23]. Hence, it was worthwhile to evaluate the effect of $\mathrm{CA}$ at varying concentrations. Thus, we studied the dosing effect of CA at five different concentrations $(0.25-2 \% \mathrm{w} / \mathrm{v})$. Induction at $20{ }^{\circ} \mathrm{C}$ in the presence of CA resulted in enhanced EDIII secretion at all concentrations (Figs. 1a and 2a). Notably,

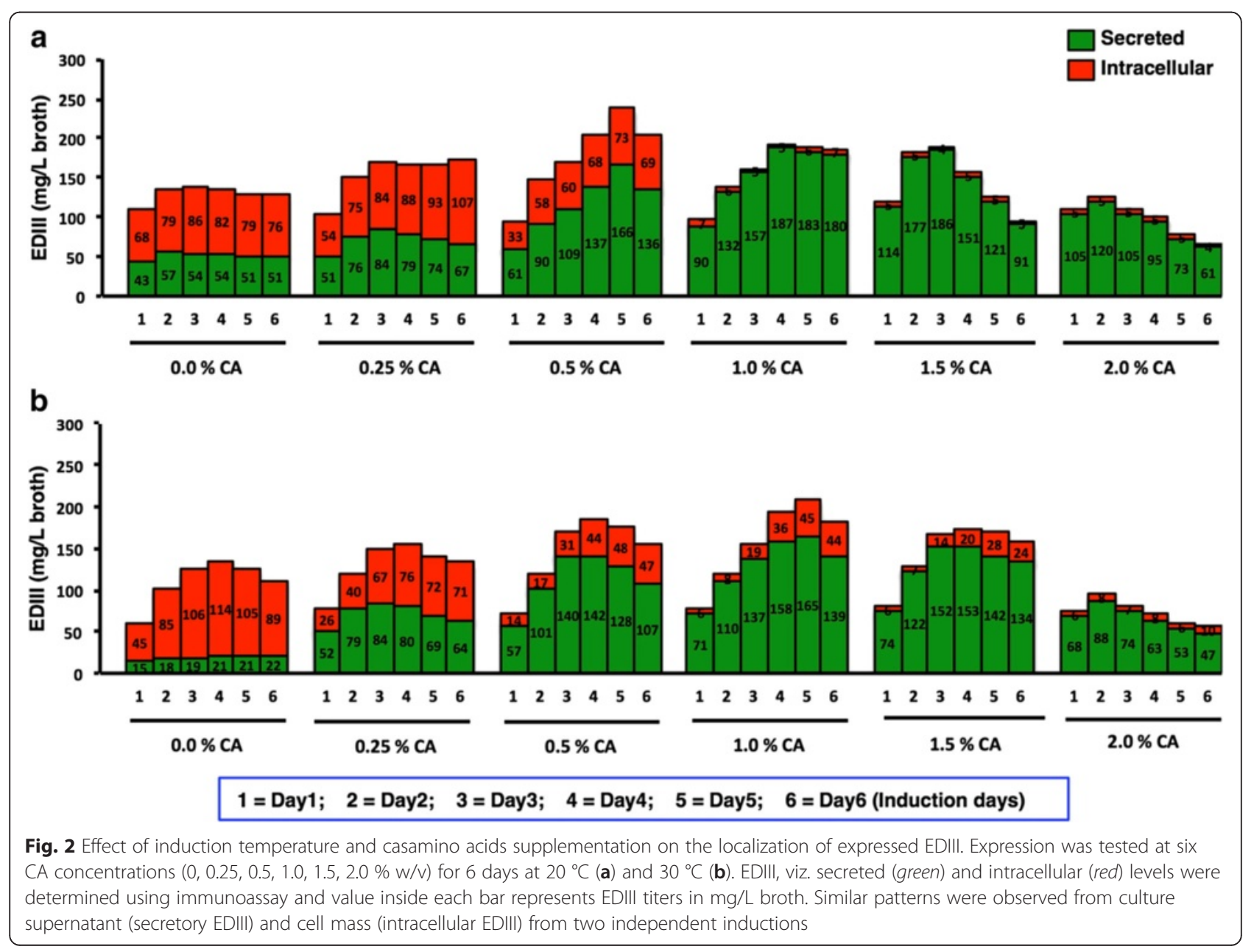



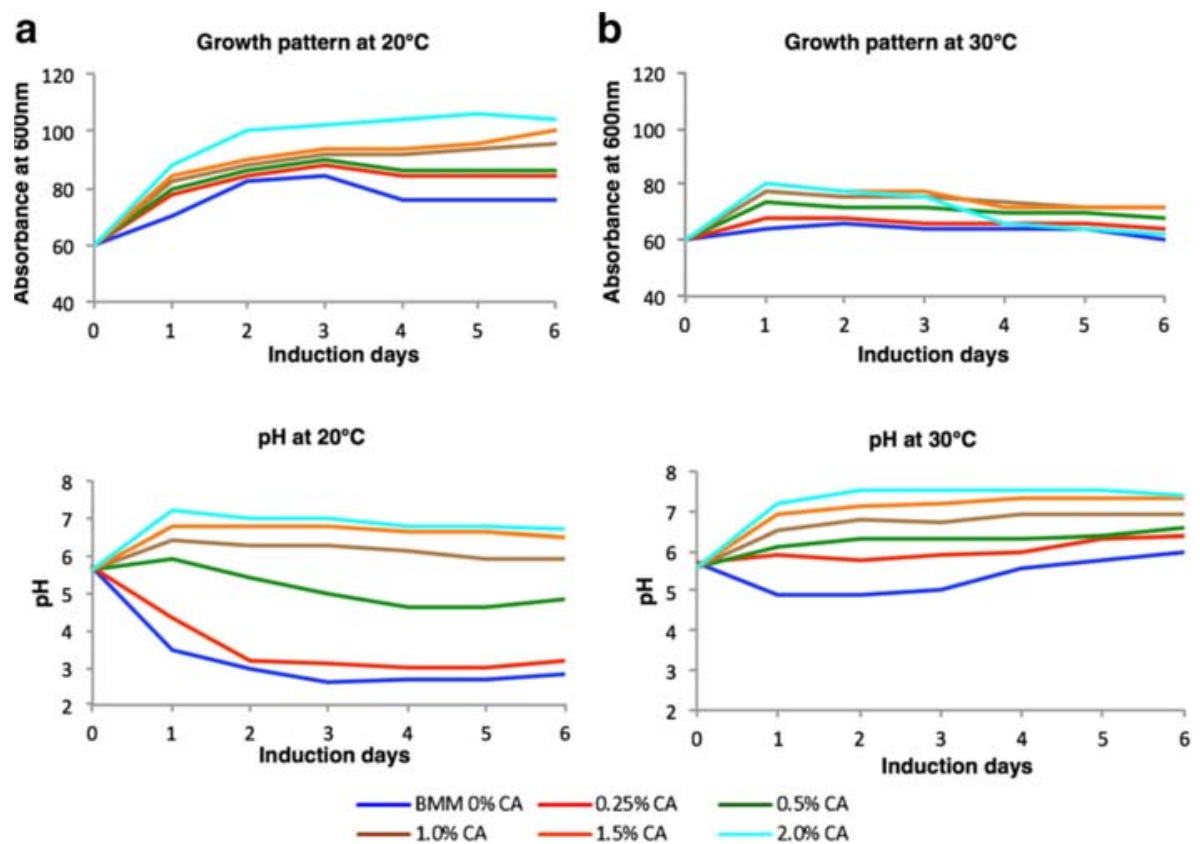

Fig. 3 Effect of temperature and CA supplementation on cell growth and culture pH. Cultures induced at $20{ }^{\circ} \mathrm{C}(\mathbf{a})$ and $30{ }^{\circ} \mathrm{C}(\mathbf{b})$ were observed for variation in growth profile (top) and $\mathrm{pH}$ (bottom) over time (days). Growth profile was determined by measuring the cell density for each time point at $600 \mathrm{~nm}$. Cells were harvested and $\mathrm{pH}$ was measured for the retrieved cell-free media. Tables containing absolute $\mathrm{OD}_{600}$ and $\mathrm{pH}$ values are also provided as additional information (Additional file 8: Table S8). Similar trends were observed in two independent induction experiments (Additional file 9)

EDIII secretory titers varied significantly between CA concentrations, with maximum EDIII accumulation $(187 \mathrm{mg} /$ $\mathrm{L}$ broth) on the $4^{\text {th }}$ day in the culture supplemented with $1 \%$ CA (Figs. 1a and 2a). This was $\sim 3.5$ times higher than the cognate condition without $\mathrm{CA}$. Interestingly a enhancement, was also observed for CA supplementation at $30{ }^{\circ} \mathrm{C}$ (Figs. $1 \mathrm{~b}$ and $2 \mathrm{~b}$ ). Surprisingly a $\sim 7.8$-fold increase in EDIII secretory titer was observed at $30{ }^{\circ} \mathrm{C}$ upon CA addition, bridging the titer gap observed earlier between $20{ }^{\circ} \mathrm{C}$ and $30{ }^{\circ} \mathrm{C}$ induction in the absence of CA. Moreover, a correlation plot of CA concentration and titer of secretory EDIII was found to be bell-shaped at both temperatures (Additional file 4: Figure S4). This suggests, that unless otherwise optimized, using an arbitrary supplementation of CA will invariably have suboptimal effect upon secretory expression of recombinant protein (Figs. 1 and 2). Notably reports suggesting negative effect of CA supplementation on the accumulation of recombinant secretory protein [23], might be due to the use of nonoptimal CA concentration for study.

A higher growth rate ( 1.3 fold) (Fig. 3a and b top) alone in the presence of CA however, cannot rationalize the observed unprecedented increase in EDIII titer. We could also observe a buffering effect of CA on culture $\mathrm{pH}$ when induced at $20^{\circ} \mathrm{C}$ (Fig. 3a, Bottom). Such an effect of CA has also been reported by others $[15,16]$. But, this might not be a decisive factor for enhanced
EDIII secretion, since the $\mathrm{pH}$ of the culture was also stable when induced at $30{ }^{\circ} \mathrm{C}$ in the absence of $\mathrm{CA}$ (Fig. 3b, Bottom). The reduction of $\mathrm{pH}$ at $20{ }^{\circ} \mathrm{C}$ in the absence of $\mathrm{CA}$ might be associated with the higher growth at $20{ }^{\circ} \mathrm{C}$ compared to $30{ }^{\circ} \mathrm{C}$ (Fig. 3). We have also observed higher growth and similar reduction in $\mathrm{pH}$ at $20{ }^{\circ} \mathrm{C}$ in $\mathrm{BMM}$ for $\mathrm{KM} 71 \mathrm{H}$ cells harboring gene-less pPICZ $\alpha$ A cassette (Additional file 5: Figure S5). CA has been associated with reduction of proteolytic activity in culture broth $[7,15,18,20]$. However, this could only be a minor factor in enhanced EDIII accumulation, as we did not observe any significant proteolysis of EDIII in the absence of CA (Additional file 6: Figure S6). Enhancement in secretory EDIII titer was visible from Day 1 post induction in the presence of $\mathrm{CA}$, negating a mere stabilizing role of CA. In agreement, a significant decline in retained (intracellular) EDIII levels was observed upon CA supplementation in a dose-dependent manner (Fig. 2). Western blot analysis of normalized total cell lysates corroborated with this finding as EDIII was barely detected in cells induced in the presence of CA at both $20{ }^{\circ} \mathrm{C}(>0.5 \%$ $\mathrm{CA}$ ) and $30{ }^{\circ} \mathrm{C}$ ( $\left.2 \% \mathrm{CA}\right)$ (Fig. 4). The ratio of secreted/ intracellular EDIII on the $4^{\text {th }}$ day of induction was measured at $0.62\left(0 \% \mathrm{CA}, 20{ }^{\circ} \mathrm{C}\right), 37.4\left(1 \% \mathrm{CA}, 20^{\circ} \mathrm{C}\right), 0.18$ $\left(0 \% \mathrm{CA}, 30{ }^{\circ} \mathrm{C}\right)$ and 4.38 (1 \% CA, $\left.30{ }^{\circ} \mathrm{C}\right)$. These results clearly suggest a CA-dependent increase in EDIII secretion, however the reduction in intracellular 

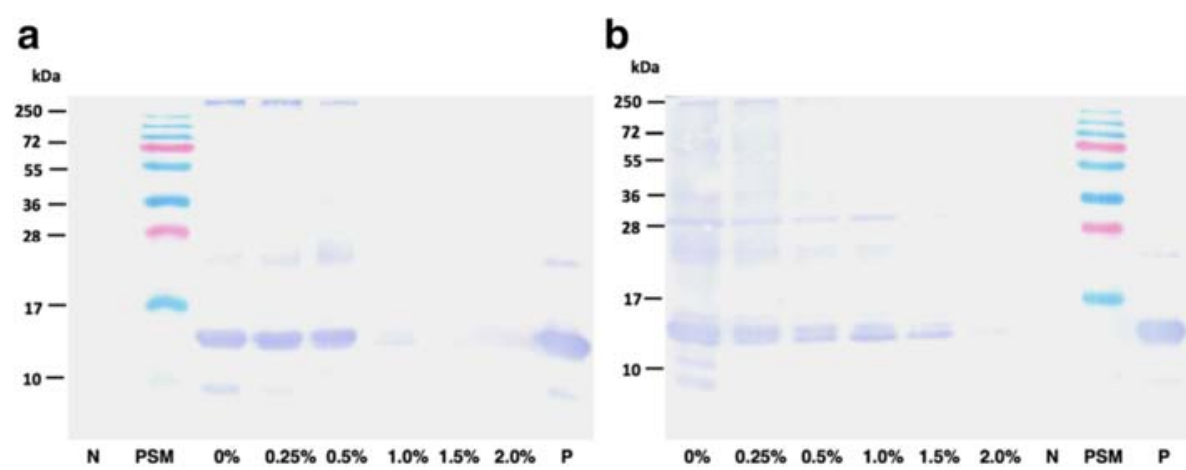

Fig. 4 Determination of intracellularly retained EDIII. Western blot of induced P. pastoris cell lysate [day 4 harvest with different CA concentration 0.0 to $2.0 \%(\mathrm{w} / \mathrm{v})$ supplemented BMM media] to determine intracellular EDIII protein at two induction temperatures. a $20^{\circ} \mathrm{C}$ induced cell lysate showing presence of $\sim 14 \mathrm{kDa}$ EDIII protein band upto $0.5 \% \mathrm{CA}(\mathrm{W} / \mathrm{v})$ whereas, $\mathbf{b} 30^{\circ} \mathrm{C}$ induced showing gradual decrease in intracellular EDIII protein from 0 to $1.5 \%$ CA (w/v). Anti-EDIII 24A12 mAb \& goat anti-mouse HRP were used as primary \& secondary antibody respectively. $\mathrm{N}$ represents negative control (KM71H cells transformed with pPICZaA) and P represents positive control (purified EDIII). Similar trends were observed with the cell mass (intracellular EDIII) obtained from two independent inductions (Additional file 9)

retention of EDIII is less prominent at $30{ }^{\circ} \mathrm{C}$ compared to $20{ }^{\circ} \mathrm{C}$.

Intracellular accumulation of protein, intended for secretion, is well described and congestion of endoplasmic reticulum (ER) folding and secretion capacity during protein trafficking is the most common rate-limiting factor $[7,13,24]$. However interestingly, intracellularly retained EDIII (without CA or at low CA concentrations) was essentially found to be in a matured form (processed $\alpha$-prepro leader sequence) especially at $20{ }^{\circ} \mathrm{C}$ (Fig. 4a), indicating that the protein was already processed at the Golgi apparatus (pro part of signal sequence cleaved by Golgi resident Kex2 protease). This indicates that ER congestion is not the main factor for intracellular EDIII retention in the absence of CA. It is possible that CA might be modulating some other non-ER checkpoints. Moreover, we cannot exclude the possibility of a cumulative effect of multiple yet unknown mechanisms modulated by CA supplementation.

Multiple strategies have been described to increase the titer of secretory protein including the use of different signal sequences, overexpression of secretion and folding aid(s), manipulation in cell-wall biogenesis and different cultivation techniques [7, 24]. However, no report associating an ameliorating effect of CA supplementation on active secretion of recombinant protein in P. pastoris exists. Though, CA supplementation has been reported to increase the accumulation of secreted recombinant protein in culture supernatant in yeast, it have often been linked to reduction in proteolytic activity in culture media [7, 15, 18, 20]. Hence, our observation of a CAdependent increase in secretion of recombinant protein, by reduction in intracellular retention of recombinant protein, makes this report very unique. Also, the observed bell-shaped correlation between CA concentration and secretory EDIII titer (Additional file 4: Figure S4) indicate that using the right concentration of CA for supplementation is key for optimal secretion of recombinant protein. However, deciphering a precise mechanism for the effect will need further experiments.

Yet another feature of the devised strategy is the titer of recombinant protein obtained (187 $\mathrm{mg} / \mathrm{L}$ broth). This is the highest reported titer for soluble EDIII, of any flavivirus, without fusion with solubility enhancing tag. A 9 fold increase in titer was achieved by supplementing with $1 \%$ CA with reduced induction temperature. Since P. pastoris secretes very low amount of host-proteins, secretion of EDIII into minimal media can be considered as the first step of purification as can be seen from the Fig. 1. The secretory EDIII was purified to apparent homogeneity from culture induced at $20{ }^{\circ} \mathrm{C}$ in the presence of $1 \% \mathrm{CA}$ in single step using Ni-affinity matrix (Fig. 5a). To determine the functionality of purified EDIII in terms of its immunogenicity and ability to elicit virus-neutralizing antibodies, mice immunizations were performed, which resulted in very high ELISA titers of anti-EDIII antibodies (Additional file 7: Figure S7). To determine the potential of anti-EDIII immune sera to block the virus infectivity, a flow cytometry based neutralization assay was performed using Vero cells [11]. This assay revealed that the purified recombinant EDIII elicits virus-blocking antibodies in mice with very high neutralizing titers against DENV-3 with $\mathrm{FNT}_{50}$ value of 986 (Fig. 5b). This suggests that the devised $P$. pastoris based over-expression strategy using $\mathrm{CA}$ as a media supplement is an efficient system for expressing recombinant EDIII. Moreover, given the significance of EDIII, the method described herein will be of immense value to small diagnostic companies and research laboratories that are not equipped with bioreactor facility for the production of recombinant EDIII. The 


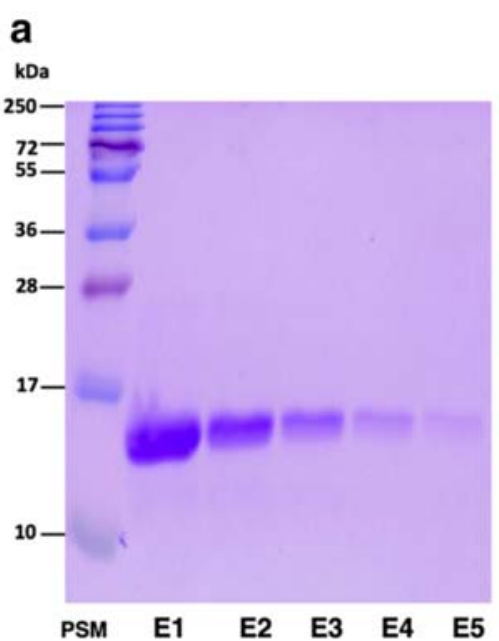

\section{b}

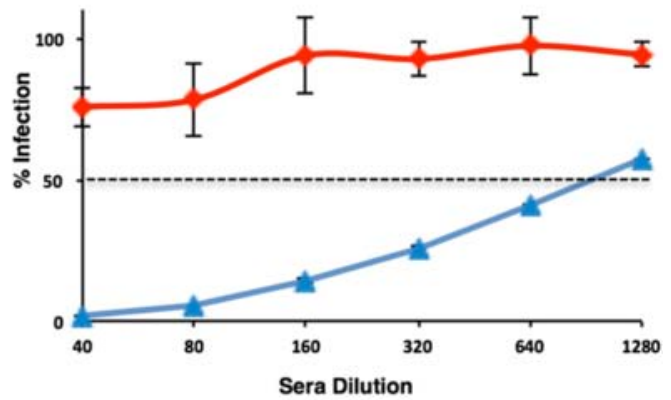

Fig. 5 Evaluation of Immunogenicity of purified recombinant EDIII. a Coomassie stained 15 \% SDS-PAGE showing purified recombinant EDIII as a $\sim 14 \mathrm{kDa}$ band in five separate elution fractions (E1 to E5) after Ni-NTA chromatography. b Determination of anti-DENV serotype-3 neutralizing antibody titers using flow-cytometry based neutralization test. Mouse anti-EDIII pooled antisera (blue) and mock pooled antisera (red) were tested at various dilutions ( $X$-axis) and percent viral infection ( $Y$-axis) was calculated. The dotted line represents $50 \%$ infection. The error bars represent standard deviation of two technical replicate

reported titer of $>150 \mathrm{mg} / \mathrm{L}$ suffices $\sim 1$ million diagnostic tests ( 100-150 ng /test) from $1 \mathrm{~L}$ of production volume and thus can circumvent the need for repeated culturing and purchase.

\section{Conclusions}

In this study we have devised an efficient strategy for enhanced secretory expression of DENV-3 EDIII in $P$. pastoris. In this process we establish a novel augmenting effect of CA upon EDIII secretion in a temperature independent manner. We also provide evidence supporting the need to decipher the correct concentration of CA for supplementation for optimal secretory expression of functional recombinant protein. To best of our knowledge, the titer obtained is the highest reported titer for soluble EDIII expression without fusion with solubility enhancing tag. The described method can find extensive usage for the production of high quality recombinant secretory proteins in $P$. pastoris in the future.

\section{Additional files}

Additional file 1: Figure S1. Multiple sequence alignment of EDIII protein from DENV serotypes. Completely conserved residues are highlighted in red background whereas partially conserved are boxed. Secondary structure assignments have been made using EsPript3.0 [25] based on PDB ID:3IRC. (PPTX $512 \mathrm{~kb}$ )

Additional file 2: Figure S2. P. pastoris optimized synthetic DENV 3 EDIII gene. DNA sequence (top) and encoded amino acid sequence (bottom). (PPTX $897 \mathrm{~kb}$ )

Additional file 3: Figure S3. Identification of the best EDIII-expressing P. pastoris clones. Levels of EDIII antigen in induced culture supernatants of several clones were estimated by Immunoassay. The $X$ - and $Y$-axis indicate the clone numbers and the corresponding EDIII antigen levels in terms of absorbance at $450 \mathrm{~nm}$, respectively. Error bars represent standard deviation of two biological replicate. Anti-EDIII 24A12 mAb \& goat anti-mouse HRP were used as primary \& secondary antibody respectively. (PPTX $736 \mathrm{~kb}$ )

Additional file 4: Figure S4. Effect of CA supplementation on the secretory titer of recombinant EDIII. Total secretory EDIII titer (mg/L) for cultures were analyzed by plotting against the concentration of CA (\%) used for induction at $20^{\circ} \mathrm{C}(\mathrm{A})$ and $30^{\circ} \mathrm{C}$ (B). A bell-shaped correlation was observed for CA concentration with the secretory titer of recombinant EDIII, advocating the importance of optimal CA concentration during induction. Error bars represent the standard deviation calculated from two technical replicate. (PPTX $1162 \mathrm{~kb}$ )

Additional file 5: Figure S5. Effect of induction temperature and CA supplementation on cell growth and culture $\mathrm{pH}(\mathrm{KM} 71 \mathrm{H}$ harboring empty vector). Cultures of $P$. pastoris $\mathrm{KM} 71 \mathrm{H}$, harboring empty pPICZaA expression cassette, induced at $20^{\circ} \mathrm{C}(\mathrm{A})$ and $30^{\circ} \mathrm{C}$ (B) were observed for variation in growth profile (top) and $\mathrm{pH}$ (bottom) over time (days). Growth profile was determined by measuring the cell density for each time point at $600 \mathrm{~nm}$. Cells were harvested and $\mathrm{pH}$ was measured for the retrieved cell-free media. (PPTX $2109 \mathrm{~kb}$ )

Additional file 6: Figure S6. Evaluating the proteolytic susceptibility of secreted EDIII in culture supernatant. Proteolytic degradation for secreted EDIII was monitored in cell-free culture supernatants to negate the balance between EDIII secretion and degradation. Culture supernatants from P. pastoris expressing EDIII in the absence of $C A$, were obtained after 6 days of induction at $20^{\circ}$ and $30^{\circ} \mathrm{C}$. Retrieved supernatants were further incubated at their respective induction temperatures and samples were collected at 0, 28 and $93 \mathrm{~h}$ interval from both. Samples were thereafter separated on a denaturing polyacrylamide gel and visualized by Coomassie stain. No visible degradation was observed indicating negligible proteolysis of secreted EDIII. Lane 1: Prestained protein marker; Lane 2-4: $20^{\circ}$ $\mathrm{C}_{i}$ Lane 5-7: $30^{\circ} \mathrm{C}_{i}$ Lane $2 \& 5: 0 \mathrm{~h}$; Lane $3 \&$ 6: $28 \mathrm{~h}$ and Lane 4 \& 7: $93 \mathrm{~h}$. (PPTX $567 \mathrm{~kb}$ )

Additional file 7: Figure S7. Evaluation of antibodies elicited by recombinant DENV-3 EDIII using ELISA. Pooled sera from EDIII immunized (solid curve) and mock (dashed curve) BALB/c mice were tested by indirect ELISA using purified EDIII as coating antigen. Goat anti-mouse HRP was used as secondary antibody. Error bars represent the standard deviation calculated from two technical replicate. (PPTX $466 \mathrm{~kb}$ ) 
Additional file 8: Table S8. Absolute values $\left(\mathrm{OD}_{600}\right.$ and $\left.\mathrm{pH}\right)$ obtained during induction phase. (DOCX $112 \mathrm{~kb}$ )

\section{Additional file 9: Data from another set of independent induction} experiment. (PDF $1054 \mathrm{~kb}$ )

\section{Abbreviations}

AOX1: alcohol oxidase 1; CA: casamino acids; DENV: dengue virus;

EDIII: envelope domain III.

\section{Competing interest}

The authors declare no conflict of interest.

\section{Authors' contributions}

GB, UL and NKh conceived and designed the study and supervised the project. NK and DR performed P. pastoris work. RR and UA performed the immunization and immune response analysis. GB and NK wrote the manuscript. All authors have read and approved the final manuscript.

\section{Acknowledgement}

This work was supported by a grant from the Department of Biotechnology, Govt. of India. We thank Bhaba Krishna Das for useful discussion and a critical review of the manuscript.

\section{Author details}

'Centre for Biodesign and Diagnostics, Translational Health Science and Technology Institute, NCR Biotech Science Cluster, Faridabad, Haryana, India. ${ }^{2}$ Recombinant Gene Products Group, International Centre for Genetic Engineering and Biotechnology, New Delhi, India. ${ }^{3}$ Department of Biochemistry/Biotechnology, University of Turku, Turku, Finland.

\section{Received: 13 October 2015 Accepted: 24 January 2016}

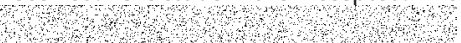

\section{References}

1. Bhatt S, Gething PW, Brady OJ, Messina JP, Farlow AW, Moyes CL, et al. The global distribution and burden of dengue. Nature. 2013;496(7446):504-7.

2. Chavez JH, Silva JR, Amarilla AA, Moraes Figueiredo LT. Domain III peptides from flavivirus envelope protein are useful antigens for serologic diagnosis and targets for immunization. Biologicals. 2010;38(6):613-8.

3. Swaminathan S, Batra G, Khanna N. Dengue vaccines: state of the art. Expert Opin Ther Pat. 2010;20(6):819-35.

4. Emmerich $\mathrm{P}$, Mika A, Schmitz H. Detection of serotype-specific antibodies to the four dengue viruses using an immune complex binding (ICB) ELISA. PLoS Negl Trop Dis. 2013;7(12):e2580.

5. Simmons M, Porter KR, Escamilla J, Graham R, Watts DM, Eckels KH, et al. Evaluation of recombinant dengue viral envelope $\mathrm{B}$ domain protein antigens for the detection of dengue complex-specific antibodies. Am J Trop Med Hyg. 1998;58(2):144-51.

6. Jaiswal S, Khanna N, Swaminathan S. High-level expression and one-step purification of recombinant dengue virus type 2 envelope domain III protein in Escherichia coli. Protein Expr Purif. 2004;33(1):80-91.

7. Macauley-Patrick S, Fazenda ML, McNeil B, Harvey LM. Heterologous protein production using the Pichia pastoris expression system. Yeast. 2005:22(4): 249-70

8. Batra G, Gurramkonda C, Nemani SK, Jain SK, Swaminathan S, Khanna N. Optimization of conditions for secretion of dengue virus type 2 envelope domain III using Pichia pastoris. J Biosci Bioeng. 2010;110(4):408-14.

9. Cardoso SA, Paixao VF, Oliveira MD, Honda ER, Oliveira LL, da Silva CC, et al. Dengue-1 envelope protein domain III produced in Pichia pastoris: potential use for serological diagnosis. Protein Expr Purif. 2013;92(1):9-13.

10. Valero F: Bioprocess Engineering of Pichia pastoris, an Exciting Host Eukaryotic Cell Expression System. In: Protein Engineering-Technology and Application. Edited by Ogawa T: InTech; 2013. http://www.intechopen.com/ books/protein-engineering-technology-and-application/bioprocessengineeringof-pichia-pastoris-an-exciting-host-eukaryotic-cell-expressionsystem

11. Kraus AA, Messer W, Haymore LB, de Silva AM. Comparison of plaque- and flow cytometry-based methods for measuring dengue virus neutralization. J Clin Microbiol. 2007;45(11):3777-80.
12. Jahic M, Wallberg F, Bollok M, Garcia P, Enfors SO. Temperature limited fedbatch technique for control of proteolysis in Pichia pastoris bioreactor cultures. Microb Cell Fact. 2003;2(1):6.

13. Zhong Y, Yang L, Guo Y, Fang F, Wang D, Li R, et al. High-temperature cultivation of recombinant Pichia pastoris increases endoplasmic reticulum stress and decreases production of human interleukin-10. Microb Cell Fact 2014;13(1):163.

14. Dragosits M, Stadlmann J, Albiol J, Baumann K, Maurer M, Gasser B, et al. The effect of temperature on the proteome of recombinant Pichia pastoris. J Proteome Res. 2009;8(3):1380-92.

15. Toonkool P, Metheenukul P, Sujiwattanarat P, Paiboon P, Tongtubtim N, Ketudat-Cairns $M$, et al. Expression and purification of dalcochinase, a betaglucosidase from Dalbergia cochinchinensis Pierre, in yeast and bacterial hosts. Protein Expr Purif. 2006;48(2):195-204.

16. Cha HJ, Dalal NN, Bentley WE. Secretion of human interleukin-2 fused with green fluorescent protein in recombinant Pichia pastoris. Appl Biochem Biotechnol. 2005:126(1):1-11.

17. Shi X, Karkut T, Chamankhah M, Alting-Mees M, Hemmingsen SM, Hegedus D. Optimal conditions for the expression of a single-chain antibody (scFv) gene in Pichia pastoris. Protein Expr Purif. 2003;28(2):321-30.

18. Clare JJ, Romanos MA, Rayment FB, Rowedder JE, Smith MA, Payne MM, et al. Production of mouse epidermal growth factor in yeast: high-level secretion using Pichia pastoris strains containing multiple gene copies. Gene. 1991;105(2):205-12.

19. Wang J, Nguyen V, Glen J, Henderson B, Saul A, Miller LH. Improved yield of recombinant merozoite Surface protein 3 (MSP3) from Pichia pastoris using chemically defined media. Biotechnol Bioeng. 2005;90(7):838-47.

20. Mukaiyama H, Giga-Hama Y, Tohda H, Takegawa K. Dextran sodium sulfate enhances secretion of recombinant human transferrin in Schizosaccharomyces pombe. Appl Microbiol Biotechnol. 2009;85(1):155-64.

21. Hu S, Li L, Qiao J, Guo Y, Cheng L, Liu J. Codon optimization, expression, and characterization of an internalizing anti-ErbB2 single-chain antibody in Pichia pastoris. Protein Expr Purif. 2006;47(1):249-57.

22. Nakamura T, Zamocky M, Zdrahal Z, Chaloupkova R, Monincova M, Prokop Z, et al. Expression of glycosylated haloalkane dehalogenase LinB in Pichia pastoris. Protein Expr Purif. 2006;46(1):85-91.

23. Schmidt SA, Tan EL, Brown S, Nasution UJ, Pettolino F, Macintyre OJ, et al. Hpf2 glycan structure is critical for protection against protein haze formation in white wine. J Agric Food Chem. 2009;57(8):3308-15.

24. Puxbaum V, Mattanovich D, Gasser B. Quo vadis? The challenges of recombinant protein folding and secretion in Pichia pastoris. Appl Microbiol Biotechnol. 2015:99(7):2925-38.

25. Robert $X$, Gouet $P$. Deciphering key features in protein structures with the new ENDscript server. Nucleic Acids Res. 2014:42(W1):W320-4.

\section{Submit your next manuscript to BioMed Central and we will help you at every step:}

- We accept pre-submission inquiries

- Our selector tool helps you to find the most relevant journal

- We provide round the clock customer support

- Convenient online submission

- Thorough peer review

- Inclusion in PubMed and all major indexing services

- Maximum visibility for your research

Submit your manuscript at www.biomedcentral.com/submit
C) Biomed Central 